\title{
COLONIALIDADES, CURRÍCULO E RELAÇÕES ÉTNICO RACIAIS: UMA ANÁLISE DOS TENSIONAMENTOS RACIAIS ENTRE CRIANÇAS NA ESCOLA
}

\author{
Pamela Cristina dos Santos ${ }^{1}$ \\ Joana Célia dos Passos²
}

\begin{abstract}
Resumo: Este trabalho apresenta resultados de uma pesquisa ação realizada em uma turma de $2^{\circ}$ ano do Ensino Fundamental de uma escola localizada na grande de Florianópolis, cujo objetivo foi compreender, a partir da lei 10.639/03 modos com que os tensionamentos raciais entre as crianças se manifestam na escola. Os tensionamentos raciais entre as crianças são apresentados através do que chamaremos de registros visuais gráficos, em outras palavras significa dizer que utilizamos de desenhos feitos a partir dos olhares das pesquisadoras como recurso metodológico. Neste fazer metodológico AFONSO (2004) destaca que uso de desenhos nas pesquisas foram, ao longo dos anos, sendo substituídos pelos avanços tecnológicos de captura de imagens, deixando estes em desuso. Refletimos que os currículos operam através da colonialidades do ser, saber e poder (QUIJANO, 2010), sendo a alteração a Lei 10.639/03 uma alternativa para a construção de uma educação igualitária, antirracista e decolonial. Nesse sentido, ressaltamos que entendemos currículo como "artefato social e histórico em constante transformação, onde os distintos fatores se entrecruzam e determinam-se mutuamente" (PASSOS, 2014, p. 177). Como resultados foi possível identificar que a branquitude através das crianças brancas e é reforçada pela estrutura escolar e curricular subalternizando as crianças negras e reforçando o racismo.
\end{abstract}

Palavras-chave: Currículo, Colonialidades, Educação das relações étnico raciais.

\section{COLONIALITIES, CURRICULUM AND ETHNIC RACIAL RELATIONS: AN ANALYSIS OF RACIAL TENSIONS BETWEEN CHILDREN IN SCHOOL}

Astract: This work presents results of an action research carried out in a class of 2nd year of Elementary School of a school located in the great city of Florianópolis, whose objective was to understand, from the law 10.639 / 03 ways in which racial tensions among children manifest themselves in school. The racial tensions between children are presented through what we will call graphic visual registers, in other words means that we use drawings made from the researchers' looks as a

\footnotetext{
${ }^{1}$ Ms. Pamela Cristina dos Santos, ALTERITAS/UFSC, Florianópolis/SC, Brasil.

${ }^{2}$ Dr $^{\mathrm{a}}$ Joana Célia dos Passos, ALTERITAS/EED/PPGE-UFSC, Florianópolis/SC, Brasil
} 
methodological resource. In this methodological approach, AFONSO (2004) emphasizes that the use of drawings in researches has been replaced over the years by the technological advances of image capture, leaving them in disuse. We reflect that curricula operate through the colonialities of being, knowledge and power (QUIJANO, 2010), and Law 10,639 / 03 is an alternative for the construction of an egalitarian, antiracist and decolonial education. In this sense, we emphasize that we understand curriculum as a "social and historical artifact in constant transformation, where the different factors intertwine and determine each other" (PASSOS, 2014, 177). As a result it was possible to identify that whiteness through white children and is reinforced by the school structure and curriculum subalternizing black children and reinforcing racism.

Keywords: Curriculum, Colonialities, Education of ethnic racial relations.

\section{INTRODUÇÃO}

Nos últimos vinte e cinco anos tivemos grandes avanços no que tange ao direitos das crianças tanto em âmbito nacional quanto internacional. A Convenção dos Direitos das Crianças (CDC) de 1989, estabeleceu uma serie de direitos para as crianças que possibilitaram que no Brasil iniciassemos discussões para aprovarmos a Lei 8.069/90 o Estatuto da Criança e do Adolescente (ECA). Dentro do campo legal para a CDC o conceito de criança é entendido como "todo o ser humano menor de 18 anos, salvo se, nos termos da lei que lhe for aplicável, atingir a maioridade mais cedo" (UNICEF, 1990, p. 6).

Ao mesmo tempo que no Brasil a partir do ECA este entendimento se altera uma vez que a legislação brasileira diz compreende por criança a "pessoa até doze anos de idade incompletos, e adolescente aquela entre doze e dezoito anos de idade (BRASIL, 1990, p. 7)". Vale destacar que o ECA foi aprovado num contexto de recente troca de regime de sociedade onde as crianças, principalmente negras e pobres, eram marginalizadas e estigmatizadas como delinquentes. Logo, num contexto politico de transição, a separação etária pode ser lida como estratégias legais de manter subalternizadas e marginalizadas as crianças consideradas delinquentes. Por esse motivo, político, adotaremos o nesta produção o conceito utilizado pela CDC.

A partir deste marco legal as produções acerca das crianças e da infância 
ganharam corpo, sendo a sociologia e psicologia as áreas pioneiras, ainda assim a educação tem sido representada nos últimos anos pela crescente de pesquisas cujo foco são as crianças e as infâncias. A partir da difusão social da criança como esse ser de pouca idade e que necessita de cuidados específicos (FERREIRA, 2004) é que nasce a preocupação com a infância, entendida como "a condição social da criança" (KULMANN, 1998, p. 31) destinada a ser um periodo de vida pelo qual as crianças passam (QVERTRUP, 2010).

Sinalizamos que grande parte das pesquisas, cujos sujeitos são crianças, não utiliza o recorte racialne/ou demais marcadores sociais, projetando um ideia de criança universalizante. Dentro do horizonte decolonial, em que raça é um eixo central de discussões, a não demarcação desta produz sujeitos abstratos e funcionais que não nos permite adentrar nas suas especificidades. Assim, com objetivo de compreender, a partir da lei 10.639/03 modos com que os tensionamentos raciais entre as crianças se manifestam na escola, marcamos que nos interessa as crianças brancas e negras vistas por ângulos capazes de dessingularizá-las, assim,

\section{CONTEXTO DA PESQUISA}

Essa pesquisa foi realizada através de intervenções pedagógicas em uma turma de segundo dos anos iniciais, com crianças de sete e oito anos de idade. As intervenções ocorreram em uma escola estadual localizada no centro de Florianópolis. Por se tratar de uma pesquisa que trabalha com dados "pouco quantificáveis" e com alto nível de produção de dados (FIGUEIREDO, 2009), esta se caracteriza como sendo de cunho qualitativo. Ainda, somada às observações dos sujeitos da pesquisa realizamos intervenções pedagógicas caracterizando esta como uma pesquisa-ação. Conceitualmente, a "pesquisa ação é uma forma de investigação que utiliza técnicas de pesquisa consagradas para informar a ação que se decide tomar para melhorar a prática" (TRIPP, 2005, p. 447).

O grupo alvo desta pesquisa era constituído por 13 crianças entre meninos e meninas. Abaixo sinalizamos em uma tabela ao mapeamento do grupo de 
crianças a partir das marcações de gênero e raça.

Tabela I: Marcadores sociais do grupo por gênero e raça

\begin{tabular}{|c|c|c|}
\hline & NEGRAS/OS & BRANCAS/OS \\
\hline MENINAS & 4 & 2 \\
\hline MENINOS & 5 & 2 \\
\hline
\end{tabular}

FONTE: elaborado pelas autoras, (2018).

Para nos amparar metodologicamente utilizamos da antropologia visual ${ }^{1}$, dentro desta corrente da antropologia, utilizamos de autores/as que teorizam sobre o uso de desenhos feitos pelo/a pesquisador/a como ferramenta de pesquisa. Assim, utilizamos desenhos elaborados a partir das observações realizadas com o referido grupo, destacamos os estudos de Lagrou (2007), Ingold (2011) que nos dizem dos desenhos enquanto "modo de pensar" que vai para além da normatividade da escrita.

O uso da linguagem visual nas pesquisas se configura como uma tentativa teórico metodológica de compor outros modos de sistematização dos conhecimentos produzidos. A produção da escrita tem dominado o meio acadêmico como principal ferramenta para a elaboração do produto final das pesquisas, deste modo nos aventuramos em ensaiar linguagens que incidem sobre a colonialidade do saber. Ainda, o uso dos desenhos nos possibilita por o nosso corpo os nossos olhares e sentir-se dentro da produção, uma vez que $o$ ato de desenhar diz tanto do pesquisador/a quanto do objeto a ser desenhado (LAGROU, 2007). Assim, neste ensaio teórico metodológico escolhemos algo menos cartesiano, nos fazendo, também, como o corpo desta pesquisa.

\section{INFÂNCIAS NA ESCOLA, MARCADORES SOCIAIS DE RAÇA E GÊNERO}

O preconceito racial no Brasil é caracterizado como de marca, ou seja, os traços fenotípicos dos sujeitos (cabelo, nariz e/ou boca somados a cor da pele) estabelessem linhas abissais que tendem a subalterniza-los/as. Nesse sentido, 0 
preconceito racial de marca age através de somatórios fenotípicos, quanto mais acentuadas as feições negras o sujeito possuir, tão maiores serão as subalternizações sociais.

Dentro do pensamento colonial moderno ocidental existem mecanismos que distanciam sujeitos negros/as da sua condição de subalternidade, como possibilidade de branqueamento social, tais como dinheiro e posições de poder. $\mathrm{Na}$ escola, além das marcações fenotípicas elementos como os materiais escolares, as roupas e os lugares escolhidos para se sentarem definem o status social que contribuem para esse processo de branqueamento.

Rosemberg (1998) afirma que em escolas onde existe o predomínio da população negra o ensino é qualificado como inferior. Sendo assim, considerando que a maior parte das crianças negras estão em escolas públicas. A afirmação da pesquisadora, feita no final do século $X X$, se arrasta até o século vigente quando os dados estatísticos, produzidos em 2014, pelo Instituto Nacional de Estudos e Pesquisas Educacionais (INEP), apontam que tempo médio de permanência na escola, de crianças entre 6 e 14 anos de idade, atingiu o número percentual de $10,7 \%$ entre crianças brancas, já para as crianças negras e/ou pardas esse número é de 9,2\%. E quando incluímos nesse dado a alfabetização, com recorte para o estado de Santa Catarina, temos, uma porcentagem de 3,2\% de analfabetismo entre brancos/as e cerca de 7,5\% entre negros/as. A partir destas colocações podemos visualizar algumas maneiras em que o racismo opera, dentro do pensamento colonial moderno ocidental, de modo a manter subalternizados/as aqueles/as que são considerados não humanos.

\section{TENSIONAMENTOS RACIAIS ENTRE CRIANÇAS, CURRÍCULO: ESTABELECENDO ALGUMAS RELAÇÕES}

As relações sociais estabelecidas nos cotidianos, aqui especificamente nos cotidianos das crianças, estão permeadas por mecanismos de naturalização da subalternidade da população negra. Desde o início da colonização foi instituído aqueles/as que seriam considerados humanos, bons e aqueles/as que seriam 
mantidos na subalternidade. Esta instituição dos papéis sociais de subalternidade e superioridade está diretamente associada a concepção de raça, assim, a ocupação de corpos não brancos em determinados espaços provocam a implosão do "Apartheid social" moderno (MBEMBE, 2016).

Ao decidirmos discutir os tensionamentos raciais entre as crianças dentro de uma espaço institucional, neste caso a escola, estamos realizando movimentos de disputa ideológica com a branquitude tal como faz a alteração da Lei de Diretrizes e Bases (LDB) a partir da lei 10.639/03 . A escola enquanto espaço normativo de saber passa pela obrigatoriedade de se moldar para contemplar a história dos sujeitos até então considerados/as, pela história colonial, não humanos. Para compreender e desvendar as tramas que envolvem os tensionamentos raciais entre crianças é que elegemos um registro gráfico (desenho) realizados a partir da intervenção pedagógica com o já referido grupo.

O registro presente na figura I, está diretamente ligado as discussões de Nogueira (1985) referente a raça enquanto marca, ao mesmo tempo que não se dissocia dos pilares estabelecidos pela branquitude em a raça é instituída apenas para sujeitos não brancos/as (SCHUCMAN, 2012).

Vejamos que uma das meninas negras do grupo que possui marcações fenotípicas acentuadas somadas com seu cabelo crespo com cachos dançantes. Já a outra menina, chamaremos aqui de Fernanda ${ }^{3}$, possui a cor da pele mais clara, mas seus cabelos também crespos estavam sempre presos, suas roupas bem alinhadas e seus materiais em mais perfeita ordem, pouco ouvia sua voz em sala. A estratégia utilizada por Fernanda para não ser enlaçada pela branquitude se pautou no silenciamento o quê em certa medida funcionou, os tensionamentos raciais registrados pouco eram direcionados a ela. Este desenho foi realizado a

\footnotetext{
${ }^{3}$ A Lei 10.639/03 foi aprovada no ano de 2003 após lutas históricas dos movimentos negros, a referida lei alterou a Lei de Diretrizes e Bases nos seus artigos 26A, 79A e 79B. A lei torna obrigatório o ensino da história e cultura afro brasileira nos currículos.
} 
partir de interações ocorridas em um momento de volta da aula de Educação Física onde desalinho do cabelo de Fernanda se acentuou, tal fato gerou uma comparação com os cabelos de Camila, ser comparada com uma menina negra ${ }^{4}$ a fez retroceder diante dos degraus de branqueamento que já tinha alcançado.

Figura 1 Registro realizado em novembro de 2016



FONTE: elaborado pelas autoras, (2017).

Os tensionamentos raciais entre as meninas, neste grupo, incidia sobre uma questão estética, ditada por um padrão branco de beleza, que avassala seus cabelos, sua pele, sua autoestima. Ainda, a figura I materializa um dos conceitos da Teoria da Representação Social (TRS), a ancoragem. Segundo MOSCOVICI (2009, p. 61) "ancorar é classificar, dar nome a alguma coisa", pois o ato de classificar e/ou nomear algo/alguém o destina a um campo de conforto que não é estranho ao referencial de normalidade. Para além disso, temos a disputa 
estabelecida pela branquitude que se atravessa pelas vozes das meninas brancas ao sinalizarem, através dos fenótipos, que Fernanda não pertencia ao mesmo grupo que elas.

Em contra partida, temos a reação incisiva da menina negra Fernanda de não querer ser comparada a colega que era alvo constante de tensões raciais e de subalternizações. Vejamos que a leitura racial realizada por Fernanda nos diz da sua percepção de que a raça é um fator de subalternização e por esse motivo se incomoda com a comparação realizada pelas colegas e se retira deste lugar.

\section{ALGUMAS CONSIDERAÇÕES}

O registro trazido para o corpo desta produção nos concederia incansáveis debates acerca das relações estabelecidas entre as crianças, sob os mais diversos focos de estudo, mas gostaríamos de utilizá-lo para salientar a importância da Educação para as Relações Étnico Raciais (ERER) nos espaços escolares. Defendemos a ERER como ferramenta de combate aos racismos cotidianos presentes nos espaços institucionais (e não só) e que se não combatidos tendem a ser enraizados nas nossas relações sociais como naturais ao invés de processos de subalternização e inferiorização da população negra.

Ainda, destacamos que pensar a ERER nos currículos exige posicionamento político frente a educação antirracista, pois esta não se constitui como um conteúdo esgotado em si mesmo. Vejamos a ERER necessita um entendimento de currículo transcende os muros escolares e que se constitui por/entre as relações estabelecidas pelos sujeitos, dentro e fora do espaço escolar. Assim, mesmo tendo as Diretrizes Nacionais e Estaduais para Educação das Relações Étnico Raciais, trabalhar ERER exige, também, percepções outras de que está precisa se fazer presente nos cotidianos.

Por fim, salientamos que nas as relações sociais estabelecidas entre crianças brancas e negras, existem mecanismos de manutenção da ideologia racista e que necessitamos de olhares atentos para estas relações nos espaços 
institucionais com intuito de assegurar legalmente os direitos das crianças negras.

\section{REFERÊNCIAS}

ARIÉS, Philippe. História Social da criança e da Família. Rio de Janeiro: LCT, 2011.

CORSARO, William. O estudo sociológico da infância. In: CORSARO, William. Sociologia da Infância. Tradução de Lia Gabriele Regius Reis. Porto Alegre: Artmed, 2011, p. 13-72.

KRAMER ,Sonia. Autoria e autorização: questões Éticas na pesquisa com crianças. Cadernos de Pesquisa, n. 116, pju.I h401/-5290,0 j2ulho/ 2002.

AZEVEDO, Aina Guimarães. Um convite à antropologia desenhada. METAgrafias: metalinguagem e outras figuras. Brasília, v. 1, n. 1 (1), p. 194-208, mar. 2016a.

BRASIL. Instituto Nacional de Estudos e Pesquisas Educacionais Anísio Teixeira. Brasília: INEP/MEC, 2003.

GOMES, Nilma L. Gomes, N. L. Trajetórias escolares, corpo negro e cabelo crespo: reprodução de estereótipos ou ressignificação cultural? São Paulo: Revista Brasileira de Educação. Associaç ão Nacional de Pós-Graduação e Pesquisa em Educação, 2000.

IBGE. Censo Demográfico, 2010. Disponível em www.ibge.gov.br. Acesso em 26/12/2017.

INGOLD, Tim. Being Alive: Essays on movement, knowledge and description. London and New York: Routledge. 279 f. 2011a.

LAGROU, Els. A fluidez da forma: arte, alteridade e agência em uma sociedade amazônica (Kaxinawa, Acre). Rio de Janeiro: Topbooks, 2007

KUSCHNIR, Karina. 2014. Ensinando antropólogos a desenhar: uma experiência didática e de pesquisa. Cadernos de Arte e Antropologia, Vol. 3, n²/2014, pag. 23-46.

LAGROU, Els. A fluidez da forma: arte, alteridade e agência em uma sociedade amazônica (Kaxinawa, Acre). Rio de Janeiro: Topbooks, 2007. 
Revista Ibero-Americana de Humanidades, Ciências e

Educação

Produção e democratização do conhecimento na Ibero-América

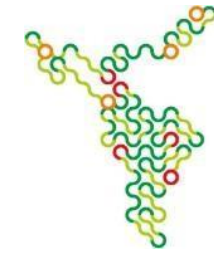

MOSCOVICI, Sérgio. Representações Sociais: investigação em psicologia social. Petrópolis, RJ: Vozes, 2003. 